\title{
An Analysis of the Determinants of Broadband Access
}

Anindya Chaudhuri

Kenneth Flamm

January 2005

DRAFT. PLEASE DO NOT CITE WITHOUT PERMISSION

Paper to be presented at The Future of Broadband: Wired \& Wireless? conference sponsored by the University of Florida and the London Business School's Global Communications Consortium; Gainesville, Florida, February 24 \& 25, 2005.

This paper was partly funded by the Pew Internet and American Life Project (www.pewinternet.org) 


\title{
An Analysis of the Determinants of Broadband Access
}

\author{
Anindya Chaudhuri ${ }^{\mathrm{a}}$ \\ Kenneth Flamm ${ }^{\mathrm{b}}$
}

\begin{abstract}
This paper extends the analysis of the relative impacts of socio-economic factors on households' decision to subscribe to dialup Internet access (Chaudhuri, Flamm and Horrigan, 2004) to the decision to subscribe to broadband. Our investigation takes into account the fact that demand for broadband may not be expressed directly because of the unavailability of supply. A simple cumulative utility (ordered logit) model is rejected in favor of a partial proportional odds model, and we find that the decision to purchase access at all, and the decision to upgrade to broadband, may be affected differently by the covariates in our model. The own-price elasticity of broadband demand is statistically significant but has a small coefficient value. The cross-price sensitivity of broadband demand with respect to dialup price is also statistically significant, and supports the notion of the two services being substitutes. These results have important policy implications for deepening broadband penetration: first, the small magnitudes of the impacts of own price suggest that untargeted price subsidies may not be a very effective tool. Second, while lower dialup prices (as have been observed in the market recently) increase Internet use, they diminish broadband demand.

${ }^{a}$ Contact Author. LBJ School of Public Affairs, The University of Texas at Austin. anindya_chaudhuri@mail.utexas.edu.

${ }^{\mathrm{b}}$ LBJ School of Public Affairs, The University of Texas at Austin.
\end{abstract}

\section{Introduction}

The evolution of Internet access technology has caused the focus of the debate on the "Digital Divide" to largely shift from dialup to broadband. The emphasis now is on "ubiquitous broadband", and ultra-highspeed wireless access may soon emerge in the limelight in policy circles. Social scientific research has been struggling to keep pace with understanding this transformative technology, but is handicapped by both the newness of the field, absence of comparative data, and the lack of firm and universally agreed upon theoretical structures. The paucity of robust estimates on the drivers of demand and supply is remarkable, given the amount of discussion expended on the topic. 
This holds true even more so for broadband than for dialup access because of the greater complexity of analysis involved.

The very basic difference between dialup and broadband is that of technical heterogeneity. Gillett (1999) points out that basic dialup access is simply an overlay over a telephone network. As a technology, this is an evolutionary dead end, and evidence points to demand already swamping existing infrastructure (Fig. 1). The Federal Communications Commission (FCC) defines any technology capable of supporting transfer of data exceeding 200kbps in at least one direction (upstream or downstream) as broadband. ${ }^{1}$ The unfortunate consequence of this obsolete definition is that there is much greater variation in speed within broadband technologies than between dialup and broadband. ${ }^{2}$

\section{[Figure 1]}

This simple delineation between dialup and broadband has caused an unfortunate semantic agglomeration of wholly unrelated technologies under the same heading. The modes of delivery of cable, digital subscriber lines (DSL), broadband over power lines (BPL), and Wi-Max are completely different. Each of them have a different set of advantages over the others, and faces a different set of technological challenges. Dialup service, both in terms of technology and in an economic sense, has attained maturity. Broadband, on the other hand, is rapidly evolving in an unpredictable manner.

\footnotetext{
${ }^{1}$ http://hraunfoss.fcc.gov/edocs public/attachmatch/FCC-04-208A1.pdf, accessed on 01/24/05.

2 Dialup, by definition, is restricted to $200 \mathrm{kbps}$. Broadband has no upper limit. Though rare in the US, residential connections at 100mbps through fiber networks are becoming common in Japan and S. Korea.
} 
This difference in maturity is the first point of departure between dialup and broadband. Though a handful of Internet service providers (ISPs) like AOL, Earthlink, and PeoplePC have national footprints, there are at present thousands of dialup ISPs dotting the country. ${ }^{3}$ This is not surprising, since dialup Internet service provision requires neither technical sophistication, nor huge capital investments. The biggest advantage is that the backbone, viz. the telephone network, already exists, and reaches almost every household in the country. ${ }^{4}$ On the other hand, even the two dominant forms of broadband, cable and xDSL, face serious technological handicaps. Cable TV penetration stands at 67.1 percent. $^{5}$ The barrier for DSL is that signal quality decreases in direct proportion to distance from the transmission point, the absolute limit being around 3 miles. Though in theory every household in the country can get satellite broadband, the question of affordability puts this out of practical consideration.

Though there is evidence that some amount of competition and price-discipline already exist (Chaudhuri \& Flamm, 2004), the presence of economies of scale in broadband implies that markets tend to be oligopolistic, and may even tend toward duopoly or even monopoly. In a small (in terms of population) but not insignificant number of geographic areas, no broadband service at all may available. This fact presents a major challenge for analyzing broadband demand, particularly when using data for earlier time periods when broadband was less ubiquitous than currently. Information on peoples' preference for

\footnotetext{
${ }^{3}$ One estimate puts the number of ISPs at 4,500 (http://www.infoworld.com/cgibin/displayNew.pl?/metcalfe/980420bm.htm, accessed on 01/16/05).

${ }^{\frac{1}{4}}$ Interestingly, households' landline subscription appears to be decreasing. In March 2004, the penetration rate stood at $94.2 \%$, which was $1.3 \%$ less than that for March 2003 . See

http://www.fcc.gov/Bureaus/Common Carrier/Reports/FCC-State_Link/Monitor/mr04-6.pdf, accessed on $01 / 16 / 05$. Of course, for providing dialup Internet access, this points to demand considerations rather than supply impediments.

${ }^{5}$ http://www.ncta.com/Docs/PageContent.cfm?pageID=86, accessed on 01/16/05.
} 
broadband may be entirely absent in many geographical areas not because the residents do not want it, but because service may simply be unavailable.

Chaudhuri, Flamm and Horrigan (2004) analyzed price, geography, and the demand for Internet access. They also included a simple model for broadband access, but the results were inconclusive because of problems with the homogeneity assumptions embedded within an ordered logit framework. This paper extends the previous analysis in a more satisfactory manner. We take our previous results obtained therein for low-speed dialup demand as fairly robust, and focus on better modeling of broadband demand. The issue of availability constraints on supply is also explicitly dealt with in our analysis.

\section{Determinants of Broadband Demand}

Analyses of demand for goods and services more often than not are based on socioeconomic determinants. This has proven true in analyzing the demand for Internet access as well. In general, these factors have proved to be robust indicators of subscription decisions. For example, reports published by the National Telecommunications and Information Administration (NTIA) have highlighted the strong correlation between race, age, and levels of income and education, and access decision. ${ }^{6}$ This has been supported by GAO (1999), UCLA (2000), and Leigh and Atkinson (2001). The general consensus is that a "digital divide" is correlated with these factors, and that the poor, the less educated, and non-whites are on the disconnected side of the divide.

\footnotetext{
${ }^{6}$ NTIA $(1995,1998,1999,2000,2002)$.
} 
Extrapolating these hypotheses to broadband is problematic both because of paucity of data and incomplete understanding of demand. It seems reasonable to suppose that these factors would, in general, affect broadband subscription decision in the same direction as they would dialup. This is supported by Rappoport, Kridel and Taylor (2002), who report that income and education are strong predictors of broadband service purchase.

However, it should be kept in mind that the dominant form of access technology for households is still dialup. ${ }^{7}$ Thus, we believe that broadband subscription decisions should be analyzed not only with non-subscription as the baseline, but vis-à-vis dialup subscription. Cable and DSL are not perceived by the public as radical new technologies; nor are they marketed as such by the providers. In general, they are more correctly perceived as providing major qualitative improvements over dialup. The point of interest hence becomes the magnitudes of the impacts of these factors on broadband access, not the direction.

A better understanding of the demand for broadband is critical to explaining the gap between dialup and broadband penetration rates. One frequently forwarded explanation is unavailability of supply, i.e. that demand is not expressed because of constraints on supply (or equivalently, that the effective price of broadband exceeds the reservation price of even the most avid potential broadband consumer). This certainly cannot be the only explanation for slow growth in broadband penetration. Secondly, as pointed out by a report published by the Florida Public Service Commission, though "broadband is

\footnotetext{
${ }^{7}$ This may or may not change in the near future, but was certainly true at the time of writing.
} 
available to $80 \%$ of households, less than $15 \%$ of those households have chosen to subscribe." 8

Hausman, Sidak and Singer (2001) state that the demographic profiles of narrowband and broadband users are very different. To support their contention, they cite two surveys conducted by the Pew Internet and American Life Project (PIALP). ${ }^{9}$ Chaudhuri and Flamm (2004) critique this inference from these two studies. They point out that the first study was based on a survey not of actual broadband users, but of dialup users showing interest in broadband connections. The second PIALP survey had a disconcertingly small sample size. Data from the Current Population Survey show that demographic differences between dialup and broadband users are hardly major. ${ }^{10}$ This is echoed by a report "Characteristics and Choices of Internet Users" by the Government Accountability Office, which finds little discernible difference between the two groups, on the basis of a much larger and more extensive survey. ${ }^{11}$

Price, though theoretically the most interesting determinant of Internet service choice, is also the least explored and understood. ${ }^{12}$ Price is important both as a key to

${ }^{8}$ http://ftp.fcc.gov/jointconference/services study-oct2002.pdf, accessed on 01/19/02.

9 "The Broadband Difference: How online Americans behavior changes with high-speed Internet connections at home." http://www.pewinternet.org/pdfs/PIP Broadband Report.pdf, accessed on 01/19/05.

${ }^{10}$ Chaudhuri and Flamm (2004).

${ }^{11} \mathrm{http}: / /$ www.gao.gov/new.items/d01345.pdf, accessed on 01/19/05.

12 The major U.S. government agencies charged with gathering information on the very high profile subject of Internet service demand have done a poor job of gathering data on what to any economist would be the first variable to come to mind when considering determinants of demand. The NTIA sponsored-surveys of computer and Internet use collected data on Internet service prices in 1998 and 2000, but then discontinued collecting the data after 2000 (this price data was never analyzed in any of the NTIA reports), for reasons that are unclear. Despite its continuing interest in broadband and high speed information services, the FCC has apparently never attempted to collect sustained data on pricing of these Internet services. The Bureau of Labor Statistics has no separate price index for these services, and appears to have made no effort to induce the Census to continue collecting this data after 2000, despite the fact that the survey used to collect this 
understanding the market and as an instrument for changing it. When comparing two markets, ceteris paribus, lower prices are usually correlated with market structure. Were the own price elasticity of broadband to prove to be high, price could also be viewed as a potential instrument shaping broadband penetration, influenced through regulation, or through subsidies.

Since broadband service is, on average, substantially more expensive than dialup service, it seems reasonable to assume that this price differential is a major market influence. A report from the Office of Technology Policy of the Department of Commerce identifies cost as "the most obvious factor limiting broadband demand". ${ }^{13}$ The report from the Florida Public Service Commission mentioned above also concludes that high price acts as an inhibitor. ${ }^{14}$ However, evidence on this matter is both sparse and unsubstantiated. Just because high prices for broadband co-exist with low penetration rates does not necessarily imply that the latter is primarily caused by the former.

There are, at present, very few academic studies on the subject. Rappoport, Kridel and Taylor (2002) find own- and cross-price elasticities for dialup, cable and ADSL connections to be statistically significant. Goolsbee (2002) derives demand curves from market survey data, and estimates the price-elasticity to range between -2.15 and -3.76 . Varian (2002) declares own-price elasticities between -1.3 and -3.1 in his INDEX trials at

information was a special supplement to it joint CPS program with Census. Indeed, the only government agency that has made any serious attempt to analyze Internet service price data is the GAO (and its 2000 study demonstrates that such data could be collected quite easily and cheaply, simply by using private market research firms as contractors).

${ }^{13} \mathrm{http}: / /$ www.technology.gov/reports/TechPolicy/Broadband 020921.pdf, accessed on 01/19/05.

$14 \mathrm{http}: / / \mathrm{ftp} . \mathrm{fcc}$.gov/jointconference/services_study-oct2002.pdf, accessed on 01/19/02. 
Berkeley. Another report from the Economic Policy Institute, quoting other studies, takes it for granted that "the demand for broadband services is very elastic". ${ }^{15}$

\section{Modeling Broadband Demand}

In an earlier paper (Chaudhuri, Flamm and Horrigan, 2004), we created a framework for analyzing Internet demand which tied together quality, price, and geographical heterogeneity. Consider a household faced with a tradeoff in purchasing some index of Internet "quality of service" and the bundle of all other goods (Fig. 2). Points A and C depict the cheapest, lowest quality service, and the most expensive, highest quality service available in the area. Point B depicts a "national" dialup plan available throughout the country at a uniform price. The budget lines for all households have to be anchored on B, but their slopes, lengths, and discontinuities (reflecting regional differences in availability of lower and higher quality services), are going to be different from one area to the other. The intersections of the three indifference curves and the budget line have the usual interpretation in terms of quality of service choice, and illustrate how regional differences in availability of services might lead to consumers purchasing lower (or higher) quality services than might be chosen had they lived in regions with a different range of service qualities offered..

\section{[Figure 2]}

\footnotetext{
15 "Putting Broadband on High Speed: New public policies to encourage rapid deployment". http://www.epinet.org/studies/broadband_pociask.pdf, accessed on 01/19/05.
} 
One key assumption made in our earlier paper is that consumer preferences were such that were a desired high price-high quality combination unavailable in a particular area, a household would always have settled for lower price, lower quality available combination. In other words, if the local market offered only the lowest quality, cheapest service, then any subscriber who would have purchased the higher priced, higher quality service would have instead purchased the cheaper service. Similarly a potential premium high-speed subscriber would have purchased the next best available broadband service, or even the best possible dialup service, were the desired service not available. This assumption about consumer preferences leads naturally to a simple binary choice model, where the decision to purchase any Internet service at all depends only on the cost of the cheapest, lowest quality service, and the availability (or lack thereof) of higher cost, higher quality services can be put aside when modeling household decisions to connect to the Internet.

Since we also assumed a simple linear relationship between price and quality, this also allowed us to model the minimum quality of service for any area, and the measured minimum price, as included in area-specific dummy variables. We then found that we could not reject the hypothesis that variation in measured minimum service prices accounted for the effects of regional dummy variables in all but a handful of the area codes that were our geographical units, i.e., that in all but a handful of exceptional cases, variation in minimum service price was sufficient to explain differences in choice probabilities across area codes. 
To model broadband demand, the simplest extension of this framework assumed a hierarchical structure in consumer preferences-- to make the decision to purchase a higher quality, higher cost bundle of Internet services dependent on a higher score on some underlying net utility measure for the household from Internet services. That is, we assume that if some function of household characteristics and minimal Internet service price exceeded a critical threshold, a household chose some form of Internet service. If this net utility function exceeded a still higher, second, threshold, then a higher quality, higher price Internet service was chosen.

This assumed relationship between a net utility function and choice of Internet service and service quality, linked to a set of threshold values before the next highest quality of service is chosen, leads naturally to an "ordered" choice model. It does depart in one significant respect from the standard ordered choice model, however, in that dialup price would be a determinant of broadband demand, but not vice-versa. That is, by only using the price of cheaper dialup service, in determining whether any Internet connection was demanded, we were implicitly excluding the price of broadband access (which may not have been available, or may not have been observed and measured in our relatively small sample) from the first-level threshold decision to purchase any Internet access at all.

Above that lowest net utility threshold (for the lowest quality and price service), on the other hand, clearly the price of the higher quality services ought to enter the decision to move up the ladder to a higher quality connection. A model of broadband demand would necessarily depend on a utility function that included a price for high speed service 
exceeding some higher threshold in order for the higher priced option to be chosen. The implication of this model structure is that the impact of high speed service price is zero when the decision threshold for any (low speed) service at all is considered, then becomes non-zero as a second, higher net utility threshold for high speed service is approached.

A model of broadband demand can only be analyzed conditional upon availability, because demand would not be expressed (and an appropriate price variable would be unavailable) in those areas where service is not available. ${ }^{16}$ One way of tackling this problem is to conduct the analysis in two steps. In the first step, we consider only those areas where broadband service is not available, and model only the demand for dialup access as a function of low speed price, along with the other socio-economic variables. In the next step, we model both low speed and high speed demand in those geographical areas where broadband service is known to be available. If our assumptions about household net utility functions are correct, then, the utility functions and thresholds for low speed service in both areas should exclude high speed service price, while utility functions and thresholds for high speed service in areas where available should include high speed price as an argument. If low speed service is a substitute for high speed service, we would also expect effect of low speed price on the high speed service decision to be positive.

\footnotetext{
${ }^{16}$ This is a simplification of the slightly more complex reality. Not only should broadband service be available in a particular area, the residents should also be aware of this fact.
} 
Thus, we would expect to observe two testable implications of asymmetry in the impacts of Internet service prices on net utility functions, as threshold values for choice of any (low speed) and broadband (high speed) services are approached. The impact of low speed service price on net utility should be negative as the threshold for any Internet service at all (the cheapest, low speed service) is approached, but should then switch to a positive effect after this threshold is crossed and the substitution of a broadband connection is next considered. Similarly, we have proposed that the impact of high speed service price is nil when any Internet service at all (low speed) is the relevant choice, and negative when a switch to high speed service from a lower speed alternative is correct. Whether our framework is a reasonable approximation to reality can be crudely tested by seeing whether the coefficients of these price variables behave as we have predicted.

Our primary dataset is the SPRING2002 from the Pew Internet and American Life Project, used in Chaudhuri, Flamm and Horrigan (2004). ${ }^{17}$ This was merged with public data from the FCC to identify households living in zip codes where broadband was available. $^{18}$ The FCC data suffered from an undercounting problem, which made some broadband subscribers to appear to live in zip codes where such service was not officially available. ${ }^{19}$ Households were thus classified as "being in broadband service available zip codes" if they satisfied either or both of two conditions: (i) they were in located in "broadband available" zip codes as identified by the FCC, and (ii) they actually subscribed to broadband.

\footnotetext{
${ }^{17}$ See Chaudhuri, Flamm and Horrigan (2004) for a discussion.

${ }_{18}$ Available at http://www.fcc.gov/wcb/iatd/comp.html, accessed on 01/24/05.

${ }^{19}$ See Flamm (2004) for a discussion.
} 
For those households which were not located in zip codes where broadband service was available, subscription was naturally not an option. In Step 1 of our analysis, demand for dialup access for these households was modeled as a simply binary logit, the covariates being socio-economic characteristics, and the minimum dialup price, by telephone area code. ${ }^{20}$ Results are presented in Table 1, and correspond to those in our earlier paper. PRICEMINLOW remains statistically significant and negative. The only major discrepancy is that the education variable(s) looses statistical significance. But this might simply be a reflection of larger standard errors from a much smaller sample size.

\section{[Table 1]}

In Step 2, the demand for both dialup and broadband access were modeled for the subsets of households in zip codes where broadband service was available. As discussed earlier, one key assumption in Chaudhuri, Flamm and Horrigan (2004) was that households purchasing more expensive broadband service would have chosen a cheaper dialup option had the broadband service been unavailable in his area. While our primary focus was to model access in general, this assumption also allowed us to extend the analysis to a hierarchical framework involving the type of purchase as well. Since it is reasonable to assume that the net utility obtained from non-access would be less than that from dialup, which would in turn be less than that from broadband, a three-level ordered logit model seemed to be a natural extension to the simple logit model.

\footnotetext{
${ }^{20}$ See Chaudhuri, Flamm and Horrigan (2004) for a discussion of the model assumptions and structure.
} 
If we categorize the purchase-decision outcome variable $(\mathrm{Y})$ as $0=$ "No purchase", $1=$ "dialup", and 2="broadband", then we can say the utilities associated with them would be ordered as $\mathrm{U}_{0} \leq \mathrm{U}_{1} \leq \mathrm{U}_{2}$. In that case, the probabilities associated with a particular outcome would be cumulative over the probabilities associated with the lower valued outcomes. Generalizing, if we assume the ranks to be $y_{1} \leq y_{2} \ldots \leq y_{k}$ for the outcome variable $\mathrm{Y}$, and defining the cumulative probabilities as:

$$
C_{i j}=\operatorname{Pr}\left(\mathrm{Y} \geq y_{j} \mid \mathbf{X}_{i}\right),
$$

where $\mathbf{X}_{i}, i=1,2, \ldots n$ is the covariate matrix, and $j=1,2, \ldots k$, we can write the cumulative (ordered) logit model as:

$$
\ln \left(\frac{C i j}{1-C i j}\right)=\beta_{0}+\beta_{1} X_{1}+\ldots+\beta_{n} X_{n} \quad j=1,2, k-1
$$

where the $\beta \mathrm{s}$ are to be estimated. The model structure implies that for each covariate, the log odds-ratios across the outcome categories are exactly the same. In other words, the marginal effect of a covariate on the transition between outcome $k$ and $k+1$ would be the same as that between $k+1$ and $k+2$. Results are shown in Table 2, but these results should NOT be considered meaningful.

\section{[Table 2]}

The reason for this is that the score test for the cumulative logit model strongly rejects the proportional odds assumption, with a chi-sq of 149.96 and a $p$-value of less than 0.0001 . This is not surprising, since all covariates displaying proportional odds is a very stringent assumption. As remarked above, our underlying conceptual framework also predicts that 
proportional odds would NOT hold-low speed price, for example, should have a negative impact on low speed access, but a positive impact on high speed access, while high speed price would have no impact on low speed access, and a negative impact on high speed access.

A much more plausible assumption would be one which permitted proportional odds for some variables, like income, but not for others, like price. As another example, it is possible that sex would have a different, or at least stronger, impact on broadband access decision, since it is a common perception that broadband is more appealing to men than to women. On the other hand, there is no a priori reason to believe that, for example, being married would make any such difference. In other words, we consider a partial proportional odds model. ${ }^{21}$

Consider the case where $p$ covariates are non-proportional in the outcome, while the rest retain the proportional odds property. In that case, the estimates of the coefficients for the first set of variables would vary across the ranks of the outcome variable. The model captured by eqn. (2) would then modify to:

$$
\ln \left(\frac{C i j}{1-C i j}\right)=\beta_{0}+\left[\beta_{I} X_{I}+\gamma_{1} D_{I}\right]+\ldots+\left[\beta_{p} X_{p}+\gamma_{p} D_{p}\right]+\ldots+\beta_{n} X_{n}, j=1,2, k-1
$$

If $\gamma_{j}=0$ for all $j$, then (3) collapses to the proportional odds model (2).

\footnotetext{
${ }^{21}$ We consider an unconstrained partial proportional odds model here. See Peterson and Harrell (1990) for a good discussion. See also Lall, Walters and Morgan (2002) and Bender and Grouven (1998).
} 
Of course, the practical problem is to identify the subset of covariates which satisfy proportional odds. For every observation, we form two logits, the first of which compares outcome 0 to 1 and 2 (i.e. access with non-access), while the second compares outcomes 0 and 1 versus 2 (non-highspeed versus highspeed). We can then consider the two logits to be separate response functions for every individual. This allows us to stack the two logits into a single model, with interaction terms between every covariate and a dummy variable marking the second logit equation. We use a Generalized Estimating Equation (GEE) estimator available through PROC GENMOD in SAS. ${ }^{22}$ In contrast to the results shown in Table 2, however, our GEE estimates are not maximum likelihood, but are consistent and somewhat more robust than maximum likelihood estimates (since we have not imposed specific distributional assumptions on our error terms), though less efficient than maximum likelihood if the logistic distributional assumptions are correct..

Table 3 shows the results of estimating a fully non-proportional odds model. We can calculate TYPE 3 score statistics for these interaction terms, identifying which interaction effects are significantly different from those of the original covariates at the broadband utility threshold. If an interaction term is significantly different from zero, it implies that that variable has an additional effect on the highspeed purchase decision over and above the simple access decision. All interaction terms which are statistically non-significant are removed, and the final model - consisting of all covariates and the subset of statistically significant interaction terms - is then estimated.

\section{[Table 3]}

${ }^{22}$ See Stokes, Davis and Koch (2000). 


\section{[Table 4]}

Table 4 present the score statistics for Type 3 GEE analysis for the interaction-terms in the "full" model. We can see that cannot reject the hypothesis that the "add-on" effects are zero for five variables - AGE, HISP, RACE, INC, and EDUC. In other words, we cannot reject the hypothesis that these variables show proportional odds between nonaccess, lowspeed access, and broadband access. Ideally, we should have used an unstructured covariance matrix in estimating our model. But because of computational problems, we had to use an identity matrix in this "selection" stage. We can see that though the Type 3 test indicates that jointly all the categories of education have no statistically significant additive effect, individually they seem to be strongly significant (Table 3). The model is then constrained by removing the other four terms, but not education, and re-estimated. The output is presented in Table 5.

\section{[Table 5]}

It should be noted that the hierarchical structure that was postulated earlier is supported by our empirical results. PRICEMINHIGH enters the demand function for only broadband, while PRICEMINLOW enters the demand for dialup with a negative coefficient, and high speed access with a net positive coefficient. We see that the effect of broadband price on broadband access is statistically significant at the 5 percent level, though the estimated value of the coefficient is not very high. It also has the appropriate negative sign, in line with theoretical priors. The cross-price impact on demand of dialup 
price is strongly statistically significant, showing the existence a reasonable degree of substitution between dialup and broadband.

In Table 4, we saw that one variable, USR had a significantly different effect on broadband access than on dialup access, in our set of "broadband available" zip codes. This was actually a categorical variable indicating location of residence - urban, suburban or rural. In our model, we picked rural as our baseline, and we can see from Table 5 that demand for broadband in suburban and urban areas is significantly higher than for dialup, relative to rural areas.

Being male appears to have strikingly different effects on the lowspeed and highspeed purchase decision. Not only is HIGH_MALE statistically significant, the estimated coefficient value - i.e. its "add-on" effect - is positive and higher than the negative and statistically significant MALE. This implies that there is a net positive impact of MALE on the probability of purchasing broadband.

We have a similar result for MARRIED, though in the opposite direction, HIGH_MARRIED being negative and highly statistically significant. This clearly runs counter to common perception, and suggests that married households, ceteris paribus, are less likely to switch to broadband than the unmarried, though they are more likely to be connected to the Internet. HIGH_STUDENT is also negative and statistically significant. However, since the estimated value of the coefficient is much less than that for STUDENT, the net effect remains positive, and student are more likely to be broadband- 
connected than non-students. This is also true for all education levels - the add-on effects appear to be negative, though the net effects remain positive.

\section{Conclusion}

In this paper, we extended our previous analysis on the determinants of Internet access in general (Chaudhuri, Flamm and Horrigan, 2004), to the demand for broadband access. The study of broadband demand is usually hampered by both questionable theoretical foundations and unavailability of price information. We sidestepped both problems by proposing a simple ordered decision structure which was a direct extension of a framework which we believe to be robust, based on earlier work. We also recognize and address the issue that broadband service itself may not be available in all areas. This methodology allows us not only to assess the effects of the determinants on broadband demand, but also compare them to the determinants of demand for dialup service.

Contrary to general perception, our most surprising outcome is that price does not seem to matter very much for broadband. Though broadband price is a statistically significant determinant of broadband demand, the very small coefficient estimate indicates very little practical impact. And, income appears to have the same positive effect on stimulating broadband demand that it does on stimulating basic Internet access (the contribution to a household's logit from moving to a higher income class is identical).

On the other hand, we do find evidence that some factors affect dialup and broadband demands very differently. In particular, though we find being male has a negative and 
statistically significant impact on the probability of dialup access, the effect is reversed for broadband access. Having an employed person in the household has no significant impact on the odds of being connected to the Internet at all (via a low speed connection), but reduces the odds of having a broadband connection, for given levels of income, education, etc.. We speculate that this may reflect the increased probability of having access to a high speed connection in a workplace setting.

Similarly, being married appears to lower the demand for broadband very slightly relative to that of a single person, though it increases demand for dialup access. This may reflect that with at least two adults in a household, the odds of some form of access to broadband in a work setting increase. Students remain more prone to use the Internet than non-students, but the stimulative effect (coefficient size) is substantially smaller for broadband than dialup, even after controlling for income. We can speculate that this perhaps reflects alternative channels of access to broadband at their educational institutions.

One striking finding is the stark contrast of urban and suburban households with their rural counterparts. Though we find that location - more precisely the degree of urbanization - plays no significant role in demand for dialup access, the story is entirely different for broadband. Not only are the rural/urban and rural/suburban differences statistically significant, the large coefficient estimates point to these gaps being relatively important. In other words, though we find no evidence for a rural-suburban-urban digital divide in demand for basic Internet access, the same cannot be said for broadband. 


\section{Reference}

1) Bender, Ralf, and Grouven, Ulrich, "Using Binary Logistic Regression Models for Ordinal Data with Non-proportional Odds." Journal of Clinical Epidemiology, Vol. 51, No. 10, pp. 809-816, 1998.

2) Chaudhuri, Anindya, and Flamm, Kenneth, "Price, Competition, and Regulating the Net", presented at the Association of Public Policy Analysis and Management (APPAM) Annual Research Conference, Atlanta, GA, October 28-30, 2004.

3) Chaudhuri, Anindya; Flamm, Kenneth, and Horrigan, John, "An Analysis of the Determinants of Internet Access", presented at the Telecommunications Policy Research Conference, Washington, DC, October 1-3, 2004.

4) Davis, Charles, S., and Koch, David G., Categorical Data Analysis Using the SAS System, Second Edition, BBU Press and John Wiley Sons Inc., 2000.

5) Gillett, Sharon Eisner, "Universal Service: Defining the Policy Goal in the Age of the Internet." 1999. http://itel.mit.edu:/itel/docs/MISC/Gillett_Universal.html, accessed 4/26/03.

6) Goolsbee, Austan, "Subsidies, the Value of Broadband, and the Importance of Fixed Costs", in Broadband: Should we Regulate High-Speed Internet Access?, Robert Crandall and James H. Alleman, eds. 2002, 278-294, Brooking Institution Press (Washington, D.C.).

7) Hausman, Jerry A., Sidak, Gregory J., and Singer, Hal J. (2001). "Residential Demand for Broadband Telecommunications and Consumer Access to Unaffiliated Internet Content Providers." Yale Journal on Regulation; Vol. 18: 129.

8) Lall, R., Walters, S.J., and Morgan, K., "A review of ordinal regression models applied on health-related quality of life assessments". Statistical Methods in Medical Research, 2002; 11: 49-67.

9) Leigh, Andrew, and Atkinson, Robert D., "Clear Thinking on the Digital Divide." 2001.

http://ksghome.harvard.edu/ .leighan.students.ksg/Subpages/pdfs/Digital\%20divide \%20report\%20PPI.pdf, accessed 4/26/03.

10) National Telecommunications and Information Administration reports, Falling Through the Net. 1995, 1998, 1999, 2000. http://www.ntia.doc.gov/ntiahome/digitaldivide, accessed 4/26/03.

11) National Telecommunications and Information Administration report, A Nation Online: How Americans are Expanding Their Use of the Internet, 2002. http://www.ntia.doc.gov/ntiahome/dn/anationonline2.pdf, accessed 4/26/03.

12) Petersen, Bercedis, and Harrell, Frank E. Jr., "Partial Proportional Odds Models for Ordinal Response Variables.” Applied Statistics, Vol. 39, No. 2 (1990), 205-217.

13) Rappaport, P., Kridel, D.J., and Taylor, L.D., (2002) "Residential Demand for Access to the Internet," Working Paper. http://www.colorado.edu/engineering/alleman/print files/Forecasting the Demand f or_Internet Services.PDF, accessed on 01/24/05.

14) The UCLA Internet Report Surveying the Digital Future. 2000. http://ccp.ucla.edu/UCLA-Internet-Report-2000.pdf, accessed 4/26/03. 
15) Varian, Hal R., "The Demand for Bandwidth: Evidence from the INDEX Projetc", 2002. http://www.sims.berkeley.edu/ hal/Papers/brookings.pdf, accessed on $01 / 25 / 05$. 


\section{Tables and Diagrams}


Figure 1

Keynote Performance Index: Average Dialup Download Speeds

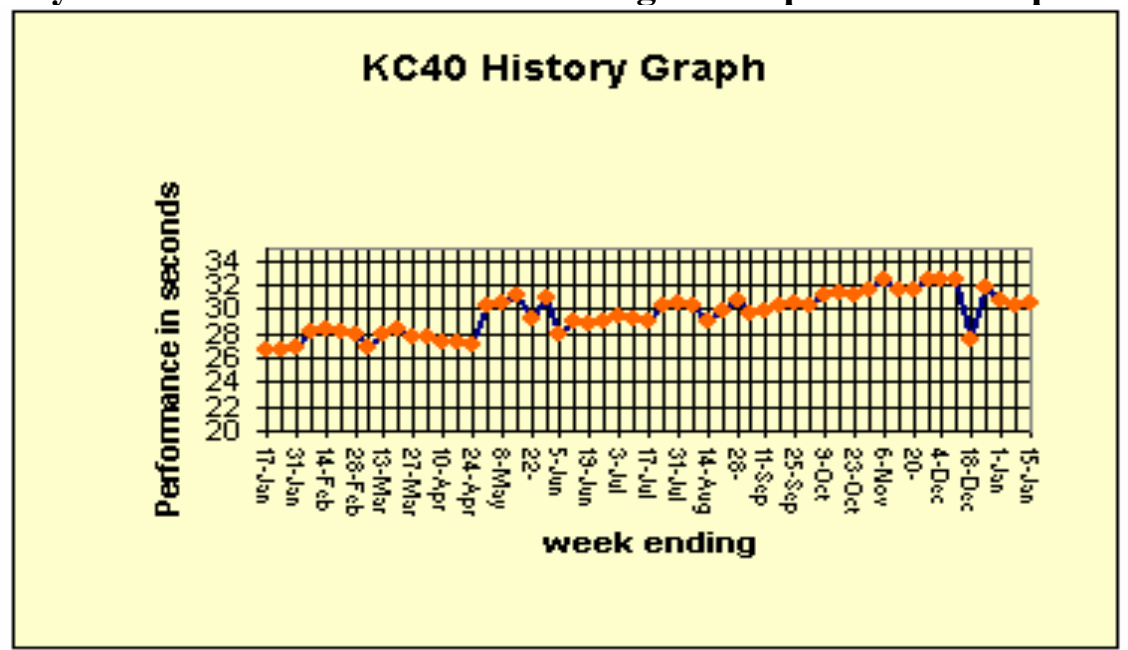

Source: http://www.keynote.com/solutions/performance indices/consumer_index/consumer_40.html, accessed on $01 / 24 / 05$

Figure 2

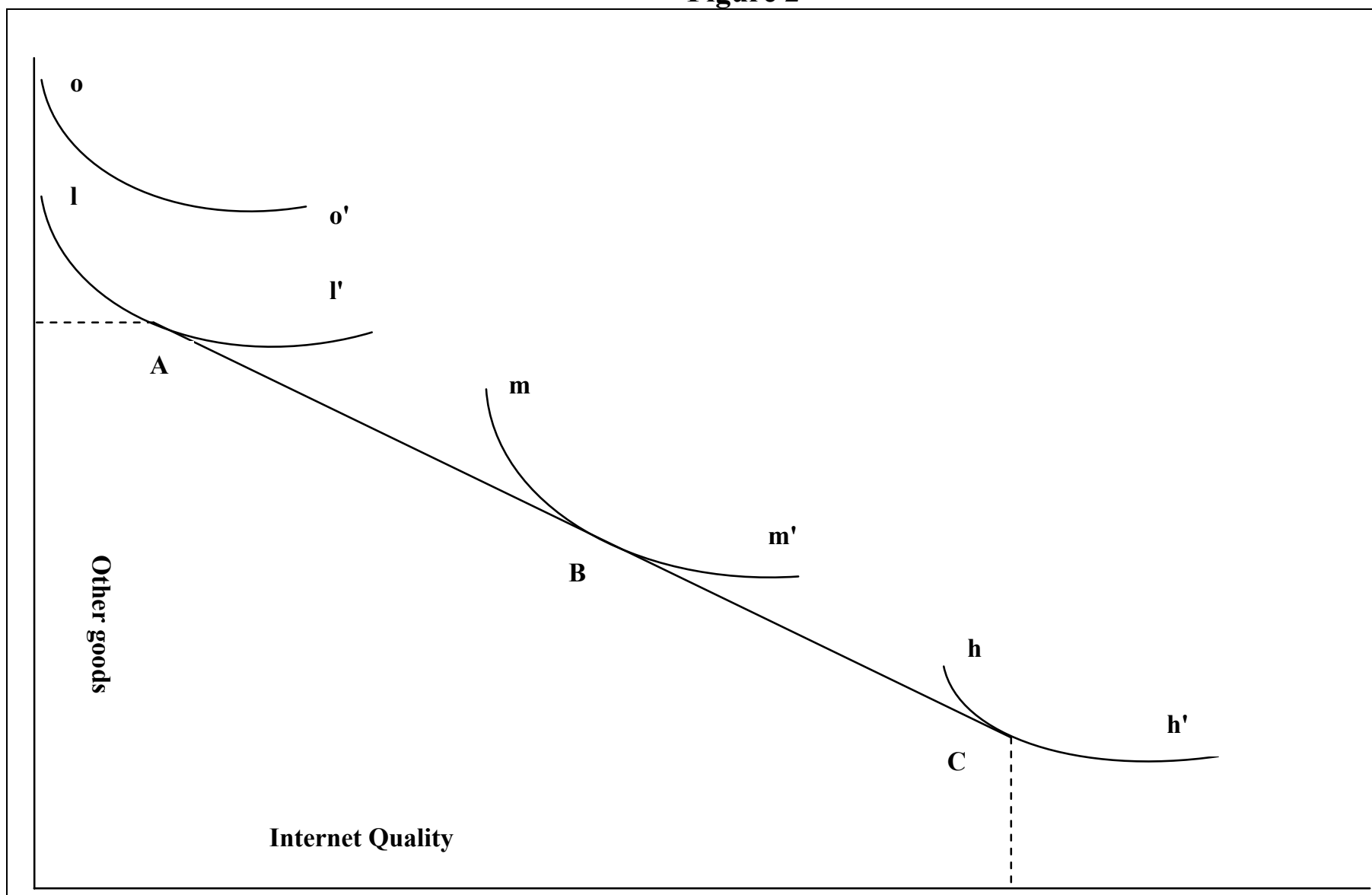


Table 1

\begin{tabular}{|l|c|c|c|}
\hline Parameter & Estimate & Pr $>$ ChiSq & Odds-Ratio \\
\hline Intercept & -0.199 & 0.873 & \\
\hline PRICEMINLOW & -0.063 & 0.001 & 0.939 \\
\hline SUBURBAN & 0.128 & 0.553 & 1.137 \\
\hline URBAN & 0.040 & 0.876 & 1.041 \\
\hline AGE & -0.026 & 0.000 & 0.975 \\
\hline MALE & -0.075 & 0.691 & 0.928 \\
\hline HISPANIC & -0.504 & 0.203 & 0.604 \\
\hline BLACK & -0.411 & 0.246 & 0.663 \\
\hline ASIAN & -1.606 & 0.090 & 0.201 \\
\hline OTHERS & -0.799 & 0.072 & 0.450 \\
\hline MARRIED & 0.586 & 0.004 & 1.796 \\
\hline EMPLOYED & -0.016 & 0.944 & 0.984 \\
\hline STUDENT & 0.662 & 0.045 & 1.939 \\
\hline INC2 & -0.094 & 0.856 & 0.910 \\
\hline INC3 & 0.722 & 0.122 & 2.058 \\
\hline INC4 & 0.972 & 0.041 & 2.644 \\
\hline INC5 & 1.705 & 0.001 & 5.499 \\
\hline INC6 & 1.550 & 0.001 & 4.709 \\
\hline INC7 & 1.548 & 0.004 & 4.704 \\
\hline INC8 & 2.110 & 0.000 & 8.251 \\
\hline EDUC2 & -0.186 & 0.873 & 0.831 \\
\hline EDUC3 & 0.522 & 0.635 & 1.685 \\
\hline EDUC4 & 1.100 & 0.344 & 3.003 \\
\hline EDUC5 & 0.960 & 0.385 & 2.612 \\
\hline EDUC6 & 1.323 & 0.237 & 3.754 \\
\hline EDUC7 & 1.449 & 0.204 & 4.258 \\
\hline
\end{tabular}

Table 2

\begin{tabular}{|l|c|c|c|}
\hline Parameter & Estimate & Pr $>$ ChiSq & Odds- Ratio \\
\hline Intercept2 & -4.008 & 0.000 & \\
\hline Intercept1 & -1.752 & 0.110 & \\
\hline PRICEMINLOW & -0.005 & 0.620 & 0.995 \\
\hline PRICEMINHIGH & -0.008 & 0.048 & 0.992 \\
\hline SUBURBAN & 0.309 & 0.036 & 1.362 \\
\hline URBAN & 0.243 & 0.142 & 1.275 \\
\hline AGE & -0.034 & $<.0001$ & 0.966 \\
\hline MALE & 0.022 & 0.842 & 1.022 \\
\hline HISPANIC & 0.017 & 0.938 & 1.017 \\
\hline BLACK & -1.079 & $<.0001$ & 0.340 \\
\hline ASIAN & -0.231 & 0.481 & 0.794 \\
\hline OTHERS & -0.142 & 0.624 & 0.868 \\
\hline MARRIED & 0.237 & 0.052 & 1.267 \\
\hline EMPLOYED & -0.033 & 0.822 & 0.968 \\
\hline
\end{tabular}




\begin{tabular}{|l|c|c|c|} 
STUDENT & 0.818 & $<.0001$ & 2.266 \\
\hline INC2 & -0.353 & 0.310 & 0.703 \\
\hline INC3 & 0.323 & 0.312 & 1.381 \\
\hline INC4 & 0.919 & 0.004 & 2.506 \\
\hline INC5 & 0.703 & 0.030 & 2.019 \\
\hline INC6 & 1.124 & 0.000 & 3.076 \\
\hline INC7 & 1.849 & $<.0001$ & 6.354 \\
\hline INC8 & 1.786 & $<.0001$ & 5.964 \\
\hline EDUC2 & 1.669 & 0.116 & 5.308 \\
\hline EDUC3 & 2.450 & 0.017 & 11.588 \\
\hline EDUC4 & 2.612 & 0.014 & 13.631 \\
\hline EDUC5 & 2.937 & 0.004 & 18.861 \\
\hline EDUC6 & 3.293 & 0.001 & 26.928 \\
\hline EDUC7 & 3.524 & 0.001 & 33.905 \\
\hline
\end{tabular}

Table 3

\begin{tabular}{|l|c|c|c|}
\hline Parameter & Estimate & $\mathbf{Z}$ & $\mathrm{Pr}>\mathbf{~ | Z |}$ \\
\hline Intercept & -1.592 & -1.310 & 0.190 \\
\hline PRICEMINLOW & -0.041 & -3.460 & 0.001 \\
\hline SUBURBAN & 0.105 & 0.600 & 0.552 \\
\hline URBAN & 0.136 & 0.680 & 0.496 \\
\hline AGE & -0.036 & -8.230 & $<.0001$ \\
\hline MALE & -0.320 & -2.310 & 0.021 \\
\hline HISPANIC & -0.114 & -0.430 & 0.667 \\
\hline BLACK & -1.297 & -5.190 & $<.0001$ \\
\hline ASIAN & -0.398 & -1.100 & 0.270 \\
\hline OTHERS & -0.237 & -0.700 & 0.482 \\
\hline MARRIED & 0.444 & 3.020 & 0.003 \\
\hline EMPLOYED & 0.101 & 0.630 & 0.530 \\
\hline STUDENT & 1.210 & 5.300 & $<.0001$ \\
\hline INC2 & -0.493 & -1.270 & 0.204 \\
\hline INC3 & 0.355 & 1.020 & 0.306 \\
\hline INC4 & 1.014 & 2.990 & 0.003 \\
\hline INC5 & 0.848 & 2.400 & 0.016 \\
\hline INC6 & 1.263 & 3.660 & 0.000 \\
\hline INC7 & 2.096 & 5.440 & $<.0001$ \\
\hline INC8 & 1.980 & 5.050 & $<.0001$ \\
\hline EDUC2 & 1.767 & 1.510 & 0.132 \\
\hline EDUC3 & 2.527 & 2.200 & 0.028 \\
\hline EDUC4 & 2.632 & 2.210 & 0.027 \\
\hline EDUC5 & 3.085 & 2.690 & 0.007 \\
\hline EDUC6 & 3.677 & 3.190 & 0.001 \\
\hline EDUC7 & 3.645 & 3.170 & 0.002 \\
\hline HIGH & -0.800 & -1.440 & 0.149 \\
\hline HIGH_PRICEMINLOW & 0.074 & 5.280 & $<.0001$ \\
\hline HIGH_PRICEMINHIGH & -0.013 & -2.180 & 0.029 \\
\hline & & & \\
\hline
\end{tabular}




\begin{tabular}{|l|c|c|c|} 
HIGH_SUBURBAN & 0.603 & 2.520 & 0.012 \\
\hline HIGH_URBAN & 0.374 & 1.420 & 0.157 \\
\hline HIGH_MALE & 0.819 & 4.810 & $<.0001$ \\
\hline HIGH_HISPANIC & 0.333 & 1.060 & 0.287 \\
\hline HIGH_BLACK & 0.673 & 2.230 & 0.025 \\
\hline HIGH_ASIAN & 0.275 & 0.640 & 0.522 \\
\hline HIGH_OTHERS & 0.089 & 0.220 & 0.829 \\
\hline HIGH_MARRIED & -0.395 & -2.210 & 0.027 \\
\hline HIGH_EMPLOYED & -0.452 & -2.360 & 0.018 \\
\hline HIGH_STUDENT & -0.736 & -2.900 & 0.004 \\
\hline HIGH_INC2 & 0.453 & 0.880 & 0.379 \\
\hline HIGH_INC3 & -0.188 & -0.380 & 0.706 \\
\hline HIGH_INC4 & -0.265 & -0.550 & 0.580 \\
\hline HIGH_INC5 & -0.512 & -1.020 & 0.310 \\
\hline HIGH_INC6 & -0.439 & -0.910 & 0.362 \\
\hline HIGH_INC7 & -0.509 & -1.000 & 0.319 \\
\hline HIGH_INC8 & -0.524 & -1.020 & 0.307 \\
\hline HIGH_EDUC2 & -1.663 & -3.380 & 0.001 \\
\hline HIGH_EDUC3 & -1.859 & -6.090 & $<.0001$ \\
\hline HIGH_EDUC4 & -1.751 & -3.620 & 0.000 \\
\hline HIGH_EDUC5 & -1.962 & -6.410 & $<.0001$ \\
\hline HIGH_EDUC6 & -2.370 & -7.380 & $<.0001$ \\
\hline HIGH_EDUC7 & -1.860 & -5.560 & $<.0001$ \\
\hline
\end{tabular}

Table 4

\begin{tabular}{|l|c|c|c|}
\hline Source & DF & Chi-Square & Pr > ChiSq \\
\hline HIGH*PRICEMINLOW & 1 & 26.360 & $<.0001$ \\
\hline HIGH*PRICEMINHIGH & 2 & 4.980 & 0.083 \\
\hline HIGH*USR & 2 & 7.010 & 0.030 \\
\hline HIGH*AGE & 1 & 1.230 & 0.268 \\
\hline HIGH ${ }^{\star}$ SEX & 1 & 23.230 & $<.0001$ \\
\hline HIGH ${ }^{*}$ HISP & 1 & 1.230 & 0.268 \\
\hline HIGH*RACE & 3 & 4.550 & 0.208 \\
\hline HIGH*MARRIED & 1 & 5.510 & 0.019 \\
\hline HIGH*EMPLOYED & 1 & 2.890 & 0.089 \\
\hline HIGH*STUDENT & 1 & 7.250 & 0.007 \\
\hline HIGH*INC & 7 & 7.090 & 0.419 \\
\hline HIGH ${ }^{*}$ EDUC & 6 & 7.730 & 0.258 \\
\hline
\end{tabular}

Table 5

\begin{tabular}{|l|c|c|c|}
\hline Parameter & Estimate & $\mathbf{Z}$ & $\operatorname{Pr}>|\mathbf{Z}|$ \\
\hline Intercept & -1.609 & -1.340 & 0.181 \\
\hline PRICEMINLOW & -0.040 & -3.420 & 0.001 \\
\hline SUBURBAN & 0.105 & 0.610 & 0.542 \\
\hline URBAN & 0.102 & 0.520 & 0.602 \\
\hline AGE & -0.036 & -8.260 & $<.0001$ \\
\hline
\end{tabular}




\begin{tabular}{|l|c|c|c|}
\hline MALE & -0.283 & -2.080 & 0.037 \\
\hline HISPANIC & 0.044 & 0.190 & 0.851 \\
\hline BLACK & -1.056 & -4.220 & $<.0001$ \\
\hline ASIAN & -0.251 & -0.860 & 0.389 \\
\hline OTHERS & -0.194 & -0.640 & 0.521 \\
\hline MARRIED & 0.514 & 3.580 & 0.000 \\
\hline EMPLOYED & 0.118 & 0.750 & 0.452 \\
\hline STUDENT & 1.130 & 5.120 & $<.0001$ \\
\hline INC2 & -0.356 & -0.960 & 0.338 \\
\hline INC3 & 0.286 & 0.880 & 0.381 \\
\hline INC4 & 0.925 & 2.900 & 0.004 \\
\hline INC5 & 0.665 & 2.020 & 0.043 \\
\hline INC6 & 1.092 & 3.430 & 0.001 \\
\hline INC7 & 1.873 & 5.600 & $<.0001$ \\
\hline INC8 & 1.750 & 5.160 & $<.0001$ \\
\hline EDUC2 & 1.757 & 1.510 & 0.131 \\
\hline EDUC3 & 2.525 & 2.220 & 0.027 \\
\hline EDUC4 & 2.668 & 2.260 & 0.024 \\
\hline EDUC5 & 3.102 & 2.730 & 0.006 \\
\hline EDUC6 & 3.717 & 3.250 & 0.001 \\
\hline EDUC7 & 3.716 & 3.240 & 0.001 \\
\hline HIGH & -0.818 & -1.730 & 0.083 \\
\hline HIGH_PRICEMINLOW & 0.072 & 5.190 & $<.0001$ \\
\hline HIGH_PRICEMINHIGH & -0.013 & -2.120 & 0.034 \\
\hline HIGH_SUBURBAN & 0.606 & 2.550 & 0.011 \\
\hline HIGH_URBAN & 0.450 & 1.720 & 0.086 \\
\hline HIGH_MALE & 0.759 & 4.470 & $<.0001$ \\
\hline HIGH_MARRIED & -0.547 & -3.230 & 0.001 \\
\hline HIGH_EMPLOYED & -0.510 & -2.690 & 0.007 \\
\hline HIGH_STUDENT & -0.601 & -2.390 & 0.017 \\
\hline HIGH_EDUC2 & -1.701 & -3.300 & 0.001 \\
\hline HIGH_EDUC3 & -1.899 & -5.930 & $<.0001$ \\
\hline HIGH_EDUC4 & -1.890 & -3.860 & 0.000 \\
\hline HIGH_EDUC5 & -2.062 & -6.510 & $<.0001$ \\
\hline HIGH_EDUC6 & -2.519 & -7.540 & $<.0001$ \\
\hline HIGH_EDUC7 & -2.056 & -5.810 & $<.0001$ \\
\hline
\end{tabular}

